\title{
Relationship between Ethics and Self-management Behaviors in the High School Student Athletes
}

\author{
Lim, Jong-Sik, Yang, Chun-Ho
}

\begin{abstract}
This study was conducted to investigate the relationship between ethics and self-management behaviors in high school student athletes. To do so, the survey was performed on 189 high school athletes that were registered in the Korean Olympic Committee in 2018. The surveyed data was processed using SPSS 21.0 statistical program with frequency, explorative factor, reliability test, correlation and multiple regression analysis. The conclusions of the study were as follows: First, positive correlations were found in respect to opponent, manners/consideration and sense of responsibility on every sub-factor of self-management behavior upon the correlation results between ethics and self-management behavior on the athletes. Positive correlations were found to cause negative psychology, judge's decision and social norms on mentality, life, unique behavior, exercise and interpersonal relationship controls. Additionally, positive correlations were found in consideration for peers and relationship with seniors on unique behavior, exercise and body controls. Second, causing negative psychology, judge's decision and social norm showed positive influences on mentality control. Respect to Opponent's respect and judge's decision showed positive influences on life control. Respect to opponent and consideration for peers showed positive influences on unique behavior and exercise controls. Causing negative psychology and respect to opponent showed positive influences on interpersonal relationship control. On the other hand, respect to opponent, consideration for peers and relationship with seniors showed positive influences on body control. In conclusion, it is suggested that ethics of the high school student athletes have a positive correlation with self-management behavior as well as partial influences.
\end{abstract}

Keywords: Self-Management, Behavior, Consciousness, Sportmanship

\section{INTRODUCTION}

$\mathbf{P}_{\text {hysical education has been empathized with the goal of }}$ whole-person education in adolescents that are in the growth period. To emphasize the importance of physical education to adolescents, the development of school athletic clubs in Korea had been initiated in the 1970s. Various school athletic clubs grew rapidly to meet the original plans [1]. This rapid growth caused notonly positive roles to the adolescents but also adverse effects to them.

Revised Manuscript Received on July 22, 2019.

Lim, Jong-Sik, Yang, 1Kunsan University, Dept. of Physical Education, Kunsan, 54150, Korea

Korea
The reality brought multiple social problems to inhibit the whole-person growth in the adolescent period. One of the serious social problems for the last few years is human rights abuse to school athletes [2]. The most important thing in normalizing the school athletic clubs is to view student athletes as students rather than athletes, and to assist them in developing their minimum level of education. With lack of the minimum level of education, they have difficulties in learning the subject classes as well as other classes due to accumulated learning absences. Moreover, they may experience the obstacles in living successful social lives.

Another problem is performance orientation. Currently, the educational reality in Korea emphasizes the importance of physical education, while student athletes concentrate on education only for entrance examinations to universities. Since they aim to win the awards from national or international contests to enter the universities, the exercises are required only for performances in contests. Performance orientation is prevailed for the student athletes to enter universities and company teams. This performance orientation became the problem on sports ethics in the student athletes. Sports ethics can be the norm or way of life for athletes to follow. This can be the principle of ethical norms at sports places. Sports ethics, which are the means to follow by sportsmen, can be found in amateurism, sportsmanship, charter of athletes, and so on. They may be known as the code of ethics to comply with.

Sports that are widely spread over society perform the functions of ethical conflict resolution or as purifiers. Since sports include the ethical value and normative meaning, they can be the most efficient ethical purifiers in our society [3]. Hence, sports have been rapidly developed due to positive reasons, such as materializations of ethical values and moral enhancement. However, the cases have increased more to misuse setting the goal only for victory in the modern sports [4]. There were some cases to skip the processes to achieve the result of wins in the sports.

Emphasizing only on the outcomes causes unethical behaviors, voluntarily or involuntarily, with behaviors against sportsmanship and rules of fair play [5]. In Korea, without exception, unethical accidents and crimes have continuously occurred in sports. This is because most of the Korean athletes learn about the obsession of winning first rather than humanity. Most of the student athletes concentrate only on the training upon been granted the position as

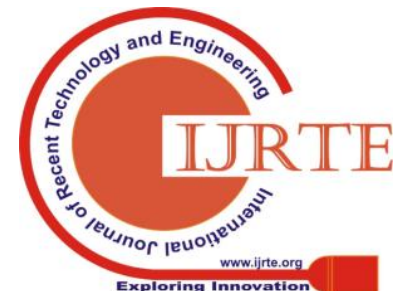


special talents on sports from their youth. The students who pass through this process will pass through the same process that they experienced after growing up as the filed leaders, such as coach, manager, and so on.

This kind of uniform development course for the athletes can be the cause of issues of today's sports in Korea. It is necessary for student athletes to change their ethics to solve the problems due to performance orientation. It is considered that student athletes will change their management and behaviors only if their ethics are changed.

Therefore, their ethics are required to be reviewed it. Therefore, this study aims to seek the direction to establish the right ethics and suggest the proper self-management behaviors in the subject of high school student athletes who are about to enter universities and company sports teams. The objective study hypotheses to achieve these goals are as follows: First, there will be a correlation between ethics and self-management behaviors in high school student athletes. Second, sports ethics of high school student athletes will affect their self-management behaviors, positively. Third, daily ethics of high school student athletes will affect their self-management behaviors, positively.

\section{STUDY METHODS}

\section{A. Study subjects}

The study subjects were student athletes who had been registered in the Korean Olympic Committee in 2018, as a population. Random sampling method was used. Among 200 survey data, a total of 189 copies were used for the final analysis excluding 11 data, which were deemed to lack credibility.

\section{B. Study tools}

A survey form was used as the study tool in this study. Survey forms consisted of 3 questionnaires on the general characteristics of the study subjects, 36 questionnaires on ethics that were independent variables, and 26 questionnaires on self-management behaviors that were dependent variables. The measurements of each questionnaire were 5-point Likert Scale from 1 point with 'none,' 2 with 'unlikely,' 3 with 'normal,' 4 with 'likely,' and 5 with 'very likely.'

\subsubsection{Ethics}

With respect to the tool to measure the level of ethics in student athletes, the modified questionnaires were used with those that Han, Kim and Kwon [7] and Baek and Park[8) had used from those developed by Kwon, Jeon and Lee [6] for the personality concept structure and indexes in Korean athletes. 8 sub-variables of ethics in the student athletes were classified, including causing negative psychology, respect to opponent, consideration for peers, relationship with seniors, judge's decision, manners/consideration, sense of responsibility and social norm.

\subsubsection{Self-management behaviors}

With respect to the measurement tool for self-management behaviors in student athletes, the modified questionnaires were used with those that Kim, Lee and Ryu[10], Mun[11], and Kim and Woo [12] had used from those developed by Kim [9] for self-management behaviors of athletes. 6 sub-variables of self-management behaviors were classified including mentality, life, unique behavior, exercise, interpersonal relationship and body controls.

\section{Validity and reliability}

Validity means how accurate the concepts or contents to be measured are [13], demonstrating how accurately the developed measurement tool is applied. Exploratory factory and Cronbach's analyses were performed to verify the validity and reliability of the questionnaires in this study, and factor rotation was performed through Varimax rotation, which is a method of orthogonal rotation. In addition, Bartlett's sphericity test and KMD were performed, simultaneously.

\subsubsection{Ethics}

The selection of variables was adequate since the Bartlett's unit matrix on ethics was 4090.747, significant level was .001 , and KMD index was .865. Based on these, 8 factors were extracted from the factor analysis with 36 questionnaires explaining about $67.812 \%$ of the total variables. Eigen values of the sub-factors on ethics were causing negative psychology (.619 .754), respect to opponent (.708 .877), consideration for peers (.534 .846), relationship with seniors $(.531 \sim .810)$, judge's decision (.681 .870), manners/consideration (.605 .643), sense of responsibility (.540 .887), and social norms (.546 .731). In addition, reliability values showed relatively high levels including causing negative psychology (.829), respect to opponent (.836), consideration for peers (.841), relationship with seniors (.844), judge's decision (.836), manners/consideration (.829), sense of responsibility (.832), and social norms (.833).

\subsubsection{Self-management behaviors}

The selection of variables was adequate since the Bartlett's unit matrix on self-management behaviors was 1903.612, significant level was .001, and KMD index was .817. Based on these, 6 factors were extracted from the factor analysis with 26 questionnaires explaining about $59.971 \%$ of the total variables. The Eigen values of the sub-factors on self-management behaviors were mentality control (.684 .791), life control (.476 .715), unique behavior control (.524 .778), exercise control (.539 .731), interpersonal relationship control (.603 .718), and body control (.563 .807). In addition, the reliability values showed relatively high levels including mentality control (.833), life control (.829), unique behavior control (.829), exercise control (.832), interpersonal relationship control (.842), and body control (.843).

\section{Data collection}

Data in this study was collected from high school student athletes registered in the Korean Olympic Committee in 2018 including team plays (soccer and volleyball), individual plays (Taekwondo 
and golf), and interpersonal plays (badminton and table tennis). Before the survey, prior excuses were requested to the relevant personnel in the schools including managers and coaches. This was performed by onsite visits to the schools. For the study subjects, they were informed on study objectives and contents of the questionnaires. Moreover, voluntary written consents were received from those who agreed to be participants. It was informed that all the data would be used only for study purposes and confidentiality,

and anonymity would be secured. Structured survey questionnaires were used with self-reported methods in this study. Completed survey forms were immediately collected onsite.

\section{E. Data processing}

The collected data were 189 copies, excluding those deemed to be inappropriate for the study. Descriptive, explorative factor and reliability analyses were performed using SPSS 21.0 to confirm normal distributions as well as validity and reliability. Correlation analysis was performed to understand the relationship among variables. Multiple regression analysis was performed to understand the causal relationship among variables. The significance level was $\alpha=.05$.

\section{RESULT}

\section{A. Results of correlation analysis}

Correlation analysis was performed to understand the relationship between ethics and self-management behaviors in high school student athletes and the results are shown in "Table 1".

Table 1: Relationship between ethics and self-management behaviors

\begin{tabular}{|c|c|c|c|c|c|c|c|c|c|c|c|c|c|}
\hline & $\mathrm{A}$ & B & $\mathrm{C}$ & $\mathrm{D}$ & $\mathrm{E}$ & $\mathrm{F}$ & $G$ & $\mathrm{H}$ & I & $G$ & $\mathrm{~K}$ & $\mathrm{~L}$ & $M$ \\
\hline A & - & & & & & & & & & & & & \\
\hline $\mathrm{B}$ & $.396^{* * *}$ & - & & & & & & & & & & & \\
\hline C & .024 & -.027 & - & & & & & & & & & & \\
\hline $\mathrm{D}$ & $142^{*}$ & .063 & $.441^{* * * *}$ & - & & & & & & & & & \\
\hline $\mathrm{E}$ & $.453^{* * * *}$ & $.421^{* * * *}$ & .055 & .002 & - & & & & & & & & \\
\hline $\mathrm{F}$ & $.482^{* * * *}$ & $403^{\text {**** }}$ & $.225^{* *}$ & $.299^{* * * *}$ & $.318^{* * * *}$ & - & & & & & & & \\
\hline $\mathrm{G}$ & $.283^{* * * *}$ & $.145^{*}$ & $.424^{* * *}$ & $.326^{* * * *}$ & $.225^{* * * *}$ & $.423^{* * *}$ & - & & & & & & \\
\hline $\mathrm{H}$ & $.374^{* * *}$ & $.210^{* * * *}$ & $.221^{* *}$ & .116 & $.314^{* * * *}$ & $.463^{* * * *}$ & $.450^{* * * *}$ & - & & & & & \\
\hline I & $.803^{* * *}$ & $314^{* * * *}$ & .069 & .058 & $.481^{* * *}$ & $.345^{* * *}$ & $.264^{* * * *}$ & $436^{* * *}$ & - & & & & \\
\hline $\mathrm{J}$ & $.424^{* * * *}$ & $.553^{\text {**** }}$ & .134 & .129 & $.492^{* * * *}$ & $.390^{* * * *}$ & $.300^{* * * *}$ & $.323^{* * *}$ & $.464^{\text {**** }}$ & - & & & \\
\hline $\mathrm{K}$ & $.241^{* * *}$ & $.215^{*}$ & $.567^{* * *}$ & $.220^{* * *}$ & $.272^{* * * *}$ & $.281^{* * * *}$ & $.412^{* * * *}$ & $.358^{* * *}$ & $.187^{* * *}$ & $.365^{* * * *}$ & - & & \\
\hline $\mathrm{L}$ & $.257^{* * * *}$ & $259^{* * * *}$ & $.344^{* * * *}$ & $.276^{* * * *}$ & $.170^{*}$ & $.314^{* * *}$ & $.346^{* * * *}$ & $312^{* * *}$ & $.243^{* * * *}$ & $.359^{* * * *}$ & $.490^{* * *}$ & & \\
\hline $\mathrm{M}$ & $.562^{* * *}$ & $401^{* * * *}$ & .044 & .019 & $.275^{* * * *}$ & $.259^{* * *}$ & $.146^{*}$ & $.223^{* * * *}$ & $.444^{* * * *}$ & $.257^{* * * *}$ & $.185^{* *}$ & .134 & - \\
\hline $\mathrm{N}$ & .047 & $.233^{\text {**** }}$ & $.413^{* * * *}$ & $.342^{* * * *}$ & .075 & $.191^{* *}$ & $.230^{* * * *}$ & .138 & -.030 & $.188^{* *}$ & $.471^{* * *}$ & $.446^{* * *}$ & .019 \\
\hline
\end{tabular}

${ }^{*}<<.05,{ }^{* *} \mathrm{p}<.01,{ }^{* * * *} \mathrm{p}<.001$

A: negative psychology. B: respect to opponent. C: consideration for peers. D: relationship with seniors E: judge's decision. F: manners/consideration. G: responsibility. H: social norm. I: mentality control. J: life control. K: unique behavior control. L: exercise control. M: interpersonal relationship control. N: body control.

The As seen in "Table 1", causing negative psychology showed the positive correlations with the order of mentality control $(\mathrm{r}=.803)$, interpersonal relationship control $(\mathrm{r}=.562)$, life control $(\mathrm{r}=.424)$, exercise control $(\mathrm{r}=.257)$, and unique behavior control $(r=.241)$. Respect to opponent showed positive correlations with the order of life control $(\mathrm{r}=.553)$, interpersonal relationship control $(\mathrm{r}=.401)$, mentality control $(\mathrm{r}=.314)$, exercise control $(\mathrm{r}=.259)$, body control $(\mathrm{r}=.233)$, and unique behavior control $(\mathrm{r}=.215)$. The consideration for peers showed positive correlations with the order of unique behavior control $(\mathrm{r}=.567)$, body control $(\mathrm{r}=.413)$, and exercise control $(\mathrm{r}=.344)$. Relationship with seniors showed positive correlations with the order of body control $(\mathrm{r}=.342)$, exercise control $(\mathrm{r}=.276)$, and unique behavior control $(\mathrm{r}=.220)$. The judge's decision showed the positive correlations with the order of life control $(r=.492)$, mentality control $(\mathrm{r}=.481)$, interpersonal relationship control $(\mathrm{r}=.275)$, unique behavior control $(\mathrm{r}=272)$, and exercise control $(\mathrm{r}=.170)$. The manners/consideration showed positive correlations with the order of life control $(\mathrm{r}=.390)$, mentality control $(\mathrm{r}=.345)$, exercise control $(\mathrm{r}=.314)$, unique behavior control $(\mathrm{r}=.281)$, interpersonal relationship control $(\mathrm{r}=.259)$, and body control $(\mathrm{r}=.191)$. The sense of responsibility showed positive correlations with the order of unique behavior control $(\mathrm{r}=.412)$, exercise control $(\mathrm{r}=.346)$, life control $(\mathrm{r}=.320)$, mentality control $(\mathrm{r}=.264)$, body control $(\mathrm{r}=.230)$, and interpersonal relationship control $(\mathrm{r}=.146)$. Social norms showed positive correlations with the order of mentality control $(\mathrm{r}=.436)$, unique behavior control $(\mathrm{r}=.358)$, life control $(\mathrm{r}=.323)$, exercise control $(\mathrm{r}=.312)$, and interpersonal relationship control $(\mathrm{r}=.223)$.

\section{B. Relationship between ethics and self-management behaviors}

Multiple regression analysis was performed to understand the relationship between ethics and self-management behaviors in high school student athletes.

\section{Relationship between ethics and willpower control}


Table 2: Relationship between ethics and willpower control

\begin{tabular}{|l|l|l|l|l|l|l|}
\hline & $\mathrm{B}$ & $\mathrm{SE}$ & Beta & $t$ & tolerance & VIF \\
\hline Constant & .373 & .232 & & 1.609 & & \\
\hline Negative psychology & .766 & .053 & .757 & $14.491^{* * *}$ & .627 & 1.595 \\
\hline Respect to opponent & -.019 & .045 & -.021 & -.432 & .714 & 1.400 \\
\hline Consideration for peers & .054 & .043 & .062 & 1.250 & .690 & 1.450 \\
\hline Relationship with seniors & -.054 & .047 & -.056 & -1.155 & .732 & 1.366 \\
\hline Judge's decision & .031 & .049 & .133 & $2.682^{* *}$ & .695 & 1.438 \\
\hline Manners/consideration & .122 & .053 & .127 & $2.300^{*}$ & .565 & 1.771 \\
\hline responsibility & -.007 & .046 & -.008 & -.162 & .631 & 1.584 \\
\hline Social norm & .162 & .048 & .171 & $3.374^{* * *}$ & .665 & 1.504
\end{tabular}

$\mathrm{R}^{2}=.694$, Corrected $\mathrm{R}^{2}=.680, \mathrm{~F}=50.767$

$\mathrm{p}<.05,{ }^{* * *} \mathrm{p}<.01,{ }^{* * * *} \mathrm{p}<.001$

As seen in "Table 2", ethics showed a significant impact on mentality control $(\mathrm{F}=50.767, \mathrm{p}<.001)$, explaining about $69.4 \%\left(\mathrm{R}^{2}=.694\right)$ among the total variables. In terms of beta-value, which is a relative influence of ethics on mentality control, positive influences were found to cause negative psychology $(\beta=.757, p<.001)$, social norms $(\beta=.171$, $\mathrm{p}<.001)$, judge's decision $(\beta=.133, \quad \mathrm{p}<.01)$, and manners/consideration $(\beta=.127, \mathrm{p}<.05)$.

\section{Relationship between ethics and lifestyle control}

Table 3: Relationship between ethics and lifestyle control

\begin{tabular}{|l|l|l|l|l|l|l|}
\hline & $\mathrm{B}$ & SE & Beta & $t$ & tolerance & VIF \\
\hline Constant & .148 & .339 & & .437 & & \\
\hline Negative psychology & 110 & .077 & .100 & 1.420 & .627 & 1.595 \\
\hline Respect to opponent & 376 & .066 & .378 & $5.704^{* * *}$ & .714 & 1.400 \\
\hline Consideration for peers & .050 & .063 & .054 & .797 & .690 & 1.450 \\
\hline Relationship with seniors & .015 & .069 & .014 & .219 & .732 & 1.366 \\
\hline Judge's decision & .249 & .072 & .233 & $3.474^{* * *}$ & .695 & 1.438 \\
\hline Manners/consideration & .023 & .077 & .022 & .298 & .565 & 1.771 \\
\hline responsibility & .117 & .067 & .124 & 1.760 & .631 & 1.584 \\
\hline Social norm & .054 & .070 & .053 & .777 & .665 & 1.504 \\
\hline $\mathrm{R}^{2}=.440$, Corrected $\mathrm{R}^{2}=.415, \mathrm{~F}=17.562^{* * * *}$ \\
\hline
\end{tabular}

As seenin "Table 3", ethics had significant impacts on life control, which was statistically significant $(\mathrm{F}=17.562$, $\mathrm{p}<.001)$ explaining about $44.0 \%\left(\mathrm{R}^{2}=.440\right)$ among the total variables. In regards to the beta-value, which is a relative influence of ethics on life control, positive influences were found in respect to opponent $(\beta=.378, \mathrm{p}<.001)$ and judge's decision $(\beta=.233, \mathrm{p}<.001)$.

\section{E. Relationship between ethics and intrinsic behavior}

Table 4: Relationship between ethics and intrinsic behavior

\begin{tabular}{|l|l|l|l|l|l|l|}
\hline & $\mathrm{B}$ & $\mathrm{SE}$ & Beta & $t$ & tolerance & VIF \\
\hline Constant & -.297 & .387 & & -.768 & & \\
\hline Negative psychology & .105 & .088 & .085 & 1.195 & .627 & 1.595 \\
\hline Respect to opponent & .155 & .075 & .137 & $2.063^{*}$ & .714 & 1.400 \\
\hline Consideration for peers & .568 & .072 & .531 & $7.872^{* * *}$ & .690 & 1.450 \\
\hline Relationship with seniors & -.083 & .078 & -.069 & -1.061 & .732 & 1.366 \\
\hline Judge's decision & .119 & .082 & .098 & 1.453 & .695 & 1.438 \\
\hline Manners/consideration & -.060 & .088 & -.051 & -.678 & .565 & 1.771 \\
\hline responsibility & .114 & .076 & .105 & 1.491 & .631 & 1.584 \\
\hline Social norm & 155 & .080 & .133 & 1.936 & .665 & 1.504 \\
\hline $\mathrm{R}^{2}=.438$, Corrected $\mathrm{R}^{2}=.413, \mathrm{~F}=17.454^{* * * *}$ & & & \\
${ }^{*} \mathrm{p}<.05,{ }^{* * * *} \mathrm{p}<.001$
\end{tabular}

Asshown in "Table 4", ethics impacted on unique behavior control, statistically significantly $(\mathrm{F}=17.454, \quad \mathrm{p}<.001)$ explaining about $43.8 \%\left(\mathrm{R}^{2}=.438\right)$ among the total variables. With respect to beta-value, which is a relative influence of ethics on unique behavior control, positive influences were found in respect to opponent $(\beta=.137, \mathrm{p}<.05)$ and consideration for peers $(\beta=.531, \mathrm{p}<.001)$.
F. Relationship between ethics and training control

Table 5: Relationship between ethics and training control

\begin{tabular}{|l|l|l|l|l|l|l|}
\hline & $\mathrm{B}$ & SE & Beta & $t$ & tolerance & VIF \\
\hline Constant & .259 & .420 & & .618 & & \\
\hline Jegative psychology & .106 & .096 & .091 & 1.113 & .627 & 1.595 \\
\hline Respect to opponent & .199 & .082 & .186 & $2.439^{*}$ & .714 & 1.400 \\
\hline Consideration for peers & .229 & .078 & .227 & $2.926^{* *}$ & .690 & 1.450 \\
\hline Relationship with seniors & .107 & .085 & .095 & 1.260 & .732 & 1.366 \\
\hline udge's decision & -.039 & .089 & -.034 & -.440 & .695 & 1.438 \\
\hline Manners/consideration & .023 & .096 & .021 & .244 & .565 & 1.771 \\
\hline Lesponsibility & .108 & .083 & .106 & 1.310 & .631 & 1.584 \\
\hline Social norm & .144 & .087 & .132 & 1.661 & .665 & 1.504 \\
\hline $\mathrm{R}^{2}=.254$, Corrected $\mathrm{R}^{2}=.221, \mathrm{~F}=7.626^{* * *}$ & & & \\
\hline
\end{tabular}

Asshownin "Table 5", ethics impacted on exercise control, statistically significantly $(\mathrm{F}=7.626, \mathrm{p}<.001)$ explaining about $25.4 \%\left(\mathrm{R}^{2}=.254\right)$ among the total variables. With respect to beta-value, which is a relative influence of ethics on exercise control, positive influences were found in respect to opponent $(\beta=.186, p<.05)$ and consideration for peers $(\beta=.227, p<.01)$.

\section{G. Relationship between ethics and interpersonal relationship control}

Table 6: Relationship between ethics and interpersonal relationship control

\begin{tabular}{|c|c|c|c|c|c|c|}
\hline & $\mathrm{B}$ & SE & Beta & $t$ & tolerance & VIF \\
\hline fonstant & .844 & .397 & & 2.127 & & \\
\hline Negative psychology & .640 & .090 & .531 & $7.076^{* * *}$ & .627 & 1.595 \\
\hline Tespect to opponent & .274 & .077 & .250 & $3.558^{\text {*** }}$ & .714 & 1.400 \\
\hline Consideration for peers & .105 & .074 & .102 & 1.422 & .690 & 1.450 \\
\hline Relationship with seniors & -.105 & .080 & -.091 & -1.308 & .732 & 1.366 \\
\hline udge's decision & -.065 & .084 & -.055 & -.769 & .695 & 1.438 \\
\hline Manners/consideration & -.089 & .091 & -.078 & -.982 & .565 & 1.771 \\
\hline tesponsibility & -.019 & .078 & -.018 & -.243 & .631 & 1.584 \\
\hline \$ocial norm & .023 & .082 & .020 & .276 & .665 & 1.504 \\
\hline \multicolumn{7}{|c|}{$\mathrm{R}^{2}=.367$, Corrected $\mathrm{R}^{2}=.339, \mathrm{~F}=12.973^{* * *}$} \\
\hline
\end{tabular}

Asshown in "Table 6", ethics impacted on interpersonal relationship control, statistically significantly $(\mathrm{F}=12.973$, $\mathrm{p}<.001)$, explaining about $36.7 \%\left(\mathrm{R}^{2}=.367\right)$ among the total variables. With respect to beta-value, which is a relative influence of ethics on interpersonal relationship control, positive influences were found in causing negative psychology $(\beta=.531 \mathrm{p}<.001)$ and respect to opponent $(\beta=.250, p<.001)$.

\section{H. Relationship between ethics and body control}

Table 7: Relationship between ethics and body control

\begin{tabular}{|l|l|l|l|l|l|l|}
\hline & $\mathrm{B}$ & SE & Beta & $t$ & tolerance & VIF \\
\hline Constant & .592 & .435 & & 1.362 & & \\
\hline Negative psychology & -.111 & .099 & -.090 & -1.117 & .627 & 1.595 \\
\hline Respect to opponent & .308 & .085 & .277 & $3.649^{* * *}$ & .714 & 1.400 \\
\hline Consideration for peers & .350 & .081 & .333 & $4.312^{* * *}$ & .690 & 1.450 \\
\hline Relationship with seniors & .222 & .088 & .1891 & $2.519^{*}$ & .732 & 1.366 \\
\hline Judge's decision & -.030 & .092 & -.025 & -.321 & .695 & 1.438 \\
\hline Manners/consideration & -.023 & .099 & -.020 & -.236 & .565 & 1.771 \\
\hline nesponsibility & .015 & .086 & .014 & .174 & .631 & 1.584 \\
\hline \$ocial norm & .034 & .090 & .030 & .376 & .665 & 1.504 \\
\hline $\mathrm{R}^{2}=.264$, Corrected $\mathrm{R}^{2}=.231, \mathrm{~F}=8.026^{* * *}$ \\
p $<.05,{ }^{* * *} \mathrm{p}<.001$
\end{tabular}

Asshown in "Table 7", ethics impacted on body control, statistically significantly $(\mathrm{F}=8.026, \mathrm{p}<.001)$, explaining about $26.4 \%\left(\mathrm{R}^{2}=.264\right)$ among the total variables. With respect to beta-value, which is a relative influence of ethics on 
body control, positive influences were found in respect to opponent $(\beta=.277, \mathrm{p}<.001)$, consideration for peers $(\beta=.333$, $\mathrm{p}<.001)$, and relationship with seniors $(\beta=.189, \mathrm{p}<.05)$.

\section{DISCUSSION}

Ethics is the principle for moral values and a means for people to comply[14]. Ethics in sports is to win proudly through fair, just and right competition. Therefore, sports ethics mean to compete fairly, treating opponents impartially,

and meeting politely under the equivalent conditions. Fair play mind and sportsmanship, which are necessary conditions, as well as values of the sports to be remained are the crucial sports ethics to realize a sports mind [2]. Korean student athletes consider sports as an occupation and try to grow to be future sportsmen. For them to grow as authentic sportsmen, they should have values and ethics related to the sports, and those that are socially expected. Hence, the student athletes should have an ethical mindset, such as fair play mind and sportsmanship. This is because there are fundamental principles to conclude those behaviors that are right and which purposes are good when they meet the options that are applied continuously under the sports situation.

The reason that we should maintain ethics is because there is no certain improvement plan although unethical situations have occurred in sports, such as Mammonism, match-fixing, human rights abuse, sexual discrimination, sexual assault, violence, and so on. Thus, studies on whether the education to improve the ethics of student athletes affects individual self-management behaviors in student athletes suggests the direction of self-management behaviors through desired ethics. Therefore, it is high time to investigate the relationship between ethics and self-management behaviors on the subjects with high school student athletes. Upon the results of this study, causing negative psychology, judge's decision, manners/consideration and social norms showed positive impacts on mentality control.

Respect to opponent and judge's decision showed positive influences on life control. Respect to opponent and consideration for peers showed positive influences on unique behavior and exercise controls. Causing negative psychology and respect to opponent showed positive influences on interpersonal relationship control; and respect to opponent, consideration for peers, and relationship with seniors showed positive influences on body control. These results demonstrated the relationship between ethics and self-management behavior in high school student athletes. These can be considered to enhance life, interpersonal relation, regular exercise as well as mentality on self-management behavior that student athletes feel insufficient in understanding and recognition on the perceived ethics. Moreover, they mean helping and cheering peers as well as consideration for peers. Favorable relationships with seniors can affect body control and unique behavior control of the student athletes through exercise.
Lee [15] claimed sportsmanship, which is the attitude towards the opponent, was related to self-management [13]. He argued that the human right mind affected the attitude of social participation, supporting part of this study results. Park, Kim [16] reported that ethics of the athletes influenced not only the athletic performance but also self-management, such as exercise control, body control, interpersonal relationship control, and so on. Recently, Song, Lee[17] empathized the importance of self-management behaviors through ethics of student athletes. As seen in these results, the importance of ethics may be overlooked if the student athletes stick to the performances or outcomes too much. Since the student athletes in high schools that perform exercise with the objective of university entrance and getting jobs, lack rational determination yet, the importance of ethics should be emphasized more. To do so, it is necessary to develop educational programs and continue the education to emphasize the importance of ethics. If the importance of ethics is immediately and seamless education is performed, student athletes would show self-management behaviors with desirable direction.

\section{CONCLUSION}

This study was conducted to investigate the relationship between ethics and self-management behaviors in high school student athletes. To do so, the survey was performed in 189 high school athletes registered in the Korean Olympic Committee in 2018. The survey data was processed using SPSS 21.0 statistical program with frequency analysis, explorative factor analysis, reliability test, correlation analysis and multiple regression analysis. The conclusions for the study are as follows: First, positive correlations were found in respect to opponent, manners/consideration, and sense of responsibility on every sub-factor of self-management behavior upon the correlation results between ethics and self-management behavior in high school student athletes. Positive correlations were found to cause negative psychology, judge's decision and social norms on mentality control, life control, unique behavior control, exercise control and interpersonal relationship control. Moreover, positive correlations were found in the consideration for peers and relationship with seniors on unique behavior, exercise and body controls. Second, causing negative psychology, judge's decision and social norms showed positive influences on mentality control. Respect to opponent and judge's decision showed positive influences on life control. Respect to opponent and consideration for peers showed positive influences on unique behavior and exercise controls. Causing negative psychology and respect to opponent showed positive influences on interpersonal relationship control. On the other hand, respect to opponent, consideration for peers and relationship with seniors showed positive influences on body control. In conclusion, it is suggested that ethics of high school student athletes have a positive correlation with self-management behaviors as well as partial influences. 


\section{ACKNOWLEDGMENT}

This study was from the 2019 Academic Research Support Project of Hanseo University.

\section{REFERENCES}

1. D.H. Lee, "Exploring Desirable Direction of School Athletic Teams as an Educational Setting". Journal of Korean Society for the Study of Physical Education.17(1), 1-16, 2012.

2. S.K. Kim, "A Study on the Human Rights of Student Sports Player and the Guaranteeing of their Rights to Education". The Korean Association of Sports Law. 12(1), 11-36, 2009.

3. S.J. Park,"A Program Development and Application on Educating Sport Ethics”. Korean journal of physical education. 55(1), 37-47, 2016.

4. S.S. Beak, J.J. Park, "Exploring the Sportsmanship Internalization Process and Affecting Factors in Middle School Physical Education”. Korean Journal of Sport Pedagogy. 19(3), 85-110, 2012.

5. S.I. Chae, J.H. Kim, S.K. Han, H.K. Lee, H.S. Jang, "The Ethicality of Athletes and Alternative". Journal of Korean Society for Sport Anthropology. 7(2), 73-93, 2012.

6. S.H. Kwon, H.S. Jeon, K.C. Lee,"Conceptual Structure of In-sung for Korean Athletes and Development of In-sung Scale". Korean Society of Sport Psychology. 25(1), 115-128, 2014.

7. D.I. Han, J.W. Kim, O.R. Kwon,"Values of Oriental Ethics for Sports Leaders in Approach of Virtue Ethics: A literature review research". Philosophy of Movement. 25(2), 1-15, 2017.

8. S.Y. Beak, B.D. Park,"The Study on the Ethical Sensitivity and the Consciousness of the Vocational Ethics for the Prospective Adapted Sport Instructors". Journal of Adapted Physical Activity \& Exercise. 24(4), 23-33, 2016

9. B.J. Kim,"Measuring Self-Management Practices in Korean Athletes". Korean Journal of Sport Science. 14(4), 125-140, 2003.

10. B.S. Kim, D.H. Lee, H.S. Ryu, "Relationship between Self-Management Behavior and Sports Confidence of University Soccer Athletes”. Journal of coaching development. 14(3), 34-41, 2012.

11. C.I. Mun,"The Influences of Self-Management and Psychological Skills on Concentration among Elite Shooting Athletes". Journal of coaching development. 13(2), 47-57, 2011.

12. J.H. Kim, D.H. Woo,"Relationship of own management conduct which follows in Youth soccer player parents motion support conduct and social maturity morality". Korean Journal of sociology of sport. 21(3), 593-607, 2008.

13. K.S. Kim, "A Study on the Effects of the Consciousness of Human Rights in Senior People on Their Attitude towards Social Participation and the Mediation of Self-Efficacy"Master, Mokpo National University, 2013.

14. J.B. Seo, S.I. Kim,"The Influence of Sports Elites on Athletic Identity and Athletics Outcomes of Elite Athletes. Korean Sport Society". 16(3), 727-736, 2018.

15. S.K. Lee, "The Relationship between Self-management and Sport Burn-out on Fencers". Korean Sport Society. 9(3), 129-137, 2011.

16. S.O. Park, J.K. Kim, "A Study on the Violation of Human Rights and Efficient Measures of Student Athletes. Korean Sport Society”. 12(2), 33-44, 2014

17. N.S. Song, J.H. Lee,"Performance Role Task for Increase of Sport Human Rights in School Athlete Coach".

\section{AUTHORS PROFILE}

Lim, Jong-Sik, Kunsan University, Dept. of Physical Education, Kunsan, 54150, Korea

Yang, Chun-Ho*, Hanseo University, Dept. of Marine Sports, Seosan,31962, Korea 